\title{
En el templo de la virtud. Moral y religión en los colegios internados salesianos. Córdoba (Argentina), 1905-1930
}

\section{In the Temple of Virtue. Morals and Religion at Salesian Boarding Schools. Córdoba (Argentina), 1905-1930}

\author{
Nicolás Domingo Moretti \\ (D) 0000-0003-0158-3036 \\ Instituto de Estudios Históricos-Centro de Estudios Históricos "Prof. Carlos S. A. \\ Segreti"-CONICET, Argentina \\ morettinicolasd@gmail.com
}

Resumen: Además de llevar a cabo una amplia labor educativa basada, principalmente, en la instrucción profesional de niños y jóvenes de sectores populares, en el interior de los colegios de la Congregación Salesiana ocupó un papel protagónico la formación moral destinada a civilizar las manifestaciones del cuerpo de los escolares, acentuando de manera especial la conservación de la virtud, el pudor y la castidad. En un clima historiográfico que promueve el interés en rescatar las experiencias, las representaciones y las distintas modalidades de agencia infantil, el presente trabajo indaga sobre la actitud asumida por los niños y jóvenes alumnos de los colegios salesianos frente a dicho disciplinamiento moral, a principios del siglo xx. Una lectura atenta de testimonios que confrontan el discurso institucional permite observar el repertorio de acciones frecuentado por los asistidos aun en una institución rígidamente reglamentada como el internado.

Palabras clave: salesianos; educación; niñez; moral; religión. 
Abstract: In addition to undertaking extensive educational work based mainly on the professional instruction of children and young people from low-income sectors, within Salesian Congregation schools, moral training designed to civilize the expressions of the body of schoolchildren played a key role, with special emphasis being placed on the preservation of virtue, modesty and chastity. In a historiographic climate that encourages the recovery of experiences, representations and the various forms of children's agency, this paper explores the attitude assumed by children and young people at Salesian schools towards this moral discipline at the beginning of the 20th century. A careful reading of testimonials opposing the institutional discourse reveals the repertoire of actions performed by students even in an institution as strictly regulated as a boarding school.

Key words: Salesian; education; childhood; moral; religion.

Fecha de recepción: 24 de abril de 2017 Fecha de aceptación: 28 de septiembre de 2017

Tú que en la edad efímera que a tantos ve caer esclavos del placer que el mundo afea, guardaste con primor el lirio del candor que a Dios recrea. ${ }^{1}$

\section{INTRODUCCIÓN}

\footnotetext{
Como novel aspirante a sacerdote, Antonio Damonteira lleva hacia 1916 dos años en la casa de formación que los salesianos poseen en Bernal, destino principal de aquellos niños y jóvenes que presentan signos de vocación a la vida consagrada y son reclutados de los colegios de la congregación en las principales ciudades de Argentina. Había decidido seguir sus estudios allí, a pesar de que su familia se opusiera a la idea de verlo convertido en

1 Canto a San Luis Gonzaga. En Oraciones y ejercicios (1949, p. 77).
} 
sacerdote. Mintiendo a sus padres sobre sus intenciones, dejaría la ciudad de Córdoba entregado a un "ardiente deseo de salvar almas". Aplicado en el estudio, desde su ingreso logró obtener calificaciones sobresalientes, ganando la aprobación de sus superiores y el reconocimiento de sus compañeros. "Me corregía de los defectos y adelantaba en la piedad y en el estudio", le llegaría a comentar con orgullo a su director espiritual.

Comienza el segundo año, y los éxitos alcanzados despiertan cierta soberbia en él. Decae en la piedad, en la conducta, e incluso en sus estudios. Su mal comportamiento debilita su alma. Atacado por las "pasiones especialmente impuras" y sin tener la fuerza necesaria, va perdiendo terreno. La comunión diaria ya no da resultados. Por fin, el "enemigo" vence y Antonio peca. Ofende al Señor que tantos favores le ha hecho: "Triste y desdichado momento!" Pese a cumplir rigurosamente con el sacramento de la confesión, las caídas y levantadas se suceden sin que los consejos de sus superiores puedan remediar nada. Su vergüenza le impide confesar las "repugnantes faltas" cometidas, repitiéndose las ocasiones de pecado. Cierto día, el director lo llama y pone palabras en la boca de Antonio para que este pueda revelar sus deslices. Aun así, la confianza entre el maestro y el alumno no es lo suficientemente sólida para impedir que el joven penitente omita los pecados más severos. Le dice, sí, que solamente una vez ha "tocado con malicia las piernas de ese compañero ocultándole lo demás”. En su casa, ya de vacaciones, sabe que aquellos actos complican su regreso al noviciado. Sin embargo alumbra una esperanza. La atenta dirección espiritual del P. Tantardini, a la cual él se ha entregado, le ha permitido detener sus "hábitos impuros".

La historia de Antonio -que se desprende de la correspondencia enviada por el joven novicio al superior de los salesianos en la Argentina, P. José Vespignani, en abril de 1917-condensa algunos de los temas que intenta abordar el presente trabajo, y que tiene como centro la regulación moral de la sexualidad en los alumnos de los colegios de la Congregación Salesiana a comienzos del siglo pasado. A la par de los esfuerzos por ofrecer una formación profesional en sus escuelas de artes y oficios a los niños más humildes, la misión educativa de los salesianos incluyó una intensa labor de moralización destinada a reformar las costumbres y hábitos de los sectores populares. Esta formación moral, que tendía a regular los comportamientos públicos

${ }^{2}$ Carta de niño aspirante al Padre Inspector José Vespignani. 30 de abril de 1917. Córdoba. Caja 3. Archivo Central Salesiano (en adelante Acs), Argentina. 
y privados de los escolares, se acentuó de manera especial en el fomento de un modo de vida que se correspondiera con la conservación de la virtud, el pudor y la castidad, en el marco de una educación que pretendía civilizar las manifestaciones del cuerpo.

En las páginas que siguen, se analizan las características que asumió esa tarea puesta a conducir y administrar la sexualidad de los niños y jóvenes educados por los salesianos, al tiempo que se busca indagar sobre el modo en que dicha disciplina moral fue apropiada, resignificada y resistida por los sujetos de asistencia en el interior de esos espacios.

El interés por explorar las dimensiones experienciales y subjetivas ha sido un rasgo asumido por una historia social más atenta, en las últimas décadas, a comprender el carácter activo y reflexivo de la conducta humana. ${ }^{3}$ La revalorización de la agencia en los procesos históricos sociales se ha vinculado a una mayor atención por parte de los historiadores a las subjetividades, las experiencias, las estrategias individuales, las percepciones y los significados (Jesen y Montero, 2013). Esta "historia social desde el sujeto" nutrió las investigaciones interesadas en los establecimientos dedicados al auxilio social, donde las interpretaciones más ortodoxas sobre el control y el disciplinamiento han sido matizadas por estudios que rescatan el protagonismo de los asistidos e intentan explicar la heterogeneidad de los significados, coerciones y prácticas de los actores. La sensibilidad hacia los aspectos interpersonales de las relaciones benéficas permite dar cuenta de la pluralidad de dimensiones y modos de resistencia al poder, como así también complejizar el abordaje de las relaciones sociales y las visiones que tratan de resaltar la autonomía relativa de los sujetos históricos dentro de los constreñimientos económicos, políticos y culturales que condicionan sus vidas (Moreyra, 2014).

En lo que hace a los estudios sobre la infancia, pese a los notables avances desarrollados por este campo historiográfico en América Latina, dichas líneas de indagación abiertas por las perspectivas de esta nueva historia social no se han traducido aún en un grueso de investigaciones atentas a indagar la formas en las cuales los niños interactuaron, dialogaron, resistieron o

${ }^{3}$ Desde fines de los años setenta puede situarse la confluencia de diversas propuestas historiográficas -entre las que cabría destacar a la "microhistoria" italiana y la "historia de cada día" alemana, sumado a otros intentos de fusionar la historia con la antropología- que se esforzaron por dar a la experiencia de los actores sociales un significado frente al juego de las estructuras y a la eficacia de los procesos sociales masivos, anónimos e inconscientes (Revel, 2015, p. 12). 
se apropiaron de ideas y proyecciones diseñadas sobre ellos desde la sociedad civil, la Iglesia o el Estado. Si bien se ha remarcado con insistencia la dificultad que entraña su abordaje para los historiadores -debido en gran parte a la carencia de material empírico producido por sujetos cuyas voces aparecen generalmente mediadas por adultos-, destacar las distintas experiencias, representaciones y modalidades de agencia infantil sigue siendo una tarea pendiente (Sosenski y Rojkin, 2016, p. 9).

Con miras a enriquecer estas inquietudes, el interrogante central de este trabajo se focaliza sobre la actitud asumida por los niños y jóvenes frente a las regulaciones morales impuestas a través de determinadas prácticas, discursos y configuraciones espaciales en el internado salesiano. Testimonios como los de Antonio ${ }^{4}$-sin duda escasos, fragmentarios, nunca concluyentes pero no por eso prescindibles-, quizás nos permitan acceder al mundo de aquellos que atravesaron parte de su infancia en espacios asistenciales durante la modernización, para explorar mejor la relación entre las prácticas de los sujetos y la cultura institucional dentro de las que tuvieron lugar.

\section{"LOS APÓSTOLES DEL PROGRESO". LA CUESTIÓN SOCIAL Y EL PROYECTO EDUCATIVO SALESIANO}

La acelerada modernización experimentada por la ciudad de Córdoba en los albores del siglo xx transformó profundamente su fisonomía urbana y social. El desarrollo y expansión de la economía -vinculado principalmente al ingreso de capitales y al aluvión inmigratorio, por mencionar algunos de los fenómenos asociados a dicha experiencia- tuvieron como contrapartida el surgimiento de fuertes desajustes sociales. La exclusión, miseria y abandono de vastos sectores de la sociedad dibujaron rápidamente los contornos

${ }^{4}$ Para la elaboración de este trabajo se han utilizado, principalmente, fuentes provenientes de la misma congregación. Por un lado, han sido de suma utilidad memorias, crónicas, libros de lectura, folletos, que han permitido reconstruir parte del entramado institucional, las concepciones pedagógicas, morales y religiosas, como así también la vida cotidiana en el interior del colegio. Al mismo tiempo, el análisis realizado sobre un conjunto de correspondencias entabladas entre salesianos, superiores y alumnos, permitió trascender el discurso institucional y enfocar la mirada en las experiencias y percepciones de los actores involucrados en la tarea educativa. 
de la emergente cuestión social, observada con preocupación por la clase dirigente local.

De manera particular, el mundo infantil se vio alcanzado por estos procesos de pauperización. Como parte del nuevo paisaje urbano, cobraron visibilidad las existencias marginales de una porción importante de niños cuyas trayectorias vitales transcurrían por fuera de los espacios considerados normales para su desarrollo, como la familia y la escuela. La cuestión social de la infancia abandonada comprendió así las distintas realidades protagonizadas por los niños provenientes de los sectores populares, cuyas complejas manifestaciones de la desigualdad se exteriorizaban en los rostros de gran cantidad de huérfanos y abandonados por sus padres, de aquellos que se empleaban en precarios empleos como canillitas, lustrabotas y "changarines", o de quienes participaban como mano de obra barata de un incipiente desarrollo industrial. A la par, su presencia en los espacios urbanos se manifestó también a través de la delincuencia, ejercida tanto de manera aislada por algunos "rateros" que protagonizaban pequeños delitos, como por grupos o bandas organizadas para el asalto a toda clase de casas de comercio o a desprevenidos transeúntes de los barrios marginales.

Los mecanismos ideados para encauzar a estos menores ${ }^{5}$ se concretaron a través de la creación de organismos que reglamentaban y vigilaban sus modos de vida, sobre todo con el aumento de la atención y financiamiento de las organizaciones de beneficencia que actuaban de manera combinada con el ámbito estatal. La preocupación mostrada por la clase dirigente en cuanto al destino de estos niños corrió a la par del desarrollo en el país de una obra educativa llevada a cabo por una congregación religiosa que experimentaría una expansión sin precedentes.

Conocidos principalmente por su intensa actividad misionera en los territorios más australes de Argentina, desde el último tercio del siglo XIX los salesianos cimentaron una obra de marcado perfil social. Junto a las obras

${ }^{5}$ Desde finales del siglo xIx fue de uso corriente entre las clases dirigentes e intelectuales argentinas la categoría de "menor", para dar cuenta de aquellos niños que no lograban insertarse satisfactoriamente al sistema económico-social y, también, de aquellos a quienes el sistema educativo no lograba retener, incorporándose al trabajo o directamente a la calle (Zapiola, 2010). Sin embargo, en el interior de las instituciones salesianas, aun cuando su alumnado estaba compuesto en gran parte por esta clase de sujetos infantiles, no circulaba esta diferenciación discursiva entre "niños" y "menores", por lo que prescindimos en este trabajo de la utilización de dichas categorías. 
destinadas a evangelizar a los pueblos originarios, un sinnúmero de propuestas culturales se dispersaron por estas latitudes en pocos años, dando lugar a un protagonismo en materia educativa en las principales ciudades argentinas. ${ }^{6}$ La intensa labor pedagógica realizada entre las élites -en momentos en los que la escasa participación estatal en la resolución de los conflictos sociales derivados de la modernización dejaba el campo de acción a la filantropía y la beneficencia privada-, tendría como objetivo asegurar el flujo de donaciones hacia su causa. El carácter eminentemente social de su empresa requirió que se dedicaran muchos esfuerzos a fidelizar a una clase dirigente no siempre dispuesta a relacionarse con religiosos. El estatus de orden laica dado a los cooperadores salesianos junto al exacerbado culto hacia la figura de sus miembros, aseguró el soporte material de la misión salesiana, que paradójicamente encontraba su centro no tanto en los ámbitos de sociabilidad de las clases acomodadas como en las existencias marginales de las periferias urbanas. Esta beneficencia se tradujo en un conjunto de iniciativas que tuvieron como finalidad la educación de los hijos del pueblo.

Emulando el esquema institucional originado en Italia, la apertura de los oratorios festivos constituía el punto de inicio de cada presencia salesiana. Su originalidad e importancia residía en que debían ser una propuesta llamativa para los menores, con la finalidad de que se acercaran y tomaran un primer contacto con la congregación. Las diversiones que configuraban esas auténticas misiones urbanas debían lograr un cometido principal: alejar a los niños de los ambientes considerados inmorales. La imagen de la calle como fuente de perversión moral y de corrupción por excelencia, nutrió la perspectiva según la cual toda obra de intervención sobre la niñez desvalida debía procurar alejarla de los peligros que allí se suscitaban. Los oratorios festivos salesianos, apartando al elemento infantil de los espacios públicos, dieron respuesta a dicha demanda.

${ }^{6}$ Fundada a mediados del siglo xix por el sacerdote piamontés Juan Bosco, la Pía Sociedad de San Francisco de Sales tendría como centro de su carisma y misión la instrucción profesional y católica de los niños y jóvenes más pobres de la ciudad de Turín. Sobre los orígenes de los salesianos y su desarrollo véase Lenti (2013). Asimismo, existen obras de referencia acerca de la labor de la congregación en Argentina, tanto de su accionar misionero en la Patagonia (su primer territorio de misión fuera de Europa), como de las características que asumió su propuesta educativa en los principales centros urbanos y zonas rurales del país (Fresia, 2012; Landaburu, 2012; Moretti, 2014; Nicoletti, 2008). 
La religión articulaba la heterogeneidad de actividades que tenían lugar en el oratorio bajo una finalidad primordial. En palabras de los mismos salesianos, la "moralización por cristianización" constituía lo verdaderamente central en ese espacio informal que combinaba múltiples juegos y esparcimientos. A la par de los deportes, los sorteos y las obras de teatro, la instrucción catequística acercaba los sacramentos a grupos de niños que se definían por una escasa -y en muchos casos nula- participación en las celebraciones religiosas.

No obstante el protagonismo de los oratorios en la propuesta educativa salesiana, el combate contra la mendicidad y la delincuencia -dos aspectos de la cuestión social que se concebían unidos íntimamente- se definía en los talleres de la congregación. A través de la enseñanza práctica de un oficio se intentaba brindar a los pequeños aprendices las herramientas necesarias para que tuvieran la posibilidad de trabajar por su cuenta o emplearse en algún taller o industria, sin depender de la caridad y la asistencia. Pero más aún, en la cosmovisión salesiana la educación en el trabajo era concebida como el remedio más eficaz para reformar aquellas costumbres y hábitos adquiridos por los menores en la calle. ${ }^{7}$ El ocio y la vagancia eran contrarrestados con una sólida formación profesional que rescataba el valor del trabajo y el esfuerzo. Gracias a la educación intelectual, profesional y cristiana se lograría el objetivo de reducir la miseria y la ruina de las innumerables "víctimas del proletariado", volviéndolos hombres útiles a sí mismos, a su familia y a la sociedad. ${ }^{8}$ Sobre estos pilares se anclaba la finalidad integradora y reformista del proyecto educativo salesiano.

Si la religión ya se hacía presente en el oratorio, en el interior de los talleres la piedad contribuía a la disciplina, asegurando un control sobre las prácticas de los niños:

Y si una vez más me pedís explicación de cómo se alcanza la disciplina, la sujeción y el cariño de esos niños artesanos que, dedicados al trabajo material, careciendo aún de ordinaria cultura, fácilmente se han de sentir inclinados a instintos bajos y han de experimentar a menudo las reminiscencias de los

${ }^{7}$ Esta visión acerca de las virtudes formativas del trabajo era compartida por amplios sectores dirigentes que, lejos de denunciar las ocupaciones laborales de gran cantidad de menores, toleraban una situación que observan beneficiosa para sustraer del ocio, la mendicidad y la delincuencia a niños definidos por su marginalidad.

${ }^{8}$ Los Principios, 30 de marzo de 1901. 
hábitos de la calle; yo os puedo asegurar que la transformación de esos corazones por medio de la Piedad y Caridad es todavía más perfecta y sincera (Vespignani, 1922, p. 413).

Tan importante como el aprendizaje de las habilidades manuales que hacían a la práctica del oficio, la moral será entendida como la verdadera herramienta de transformación en una "masa proletaria y dócil"9 de aquellos a quienes la congregación definirá como sujetos preferenciales de su tarea asistencial.

\section{LA “MODESTIA”, REINA DE TODAS LAS VIRTUDES}

En una sociedad atravesada fuertemente por la cultura católica, las instituciones religiosas protagonizaron la tarea de normalizar el cuerpo social, transmitiendo valores y modales que estuvieran en armonía con los presupuestos doctrinales de la Iglesia. La moralización de la población fue, así, una tarea compartida por diversas congregaciones y órdenes con una presencia significativa a través de una red de establecimientos de todo tipo. Los salesianos, por su atención hacia la minoridad, fueron un eslabón fundamental en la educación católica de los sectores populares. La piedad, la obediencia, el trabajo, intentaron moldear el comportamiento de los escolares, junto a una formación moral que acentuó de manera particular la regulación de las pulsiones sexuales de los alumnos, destacando el cuidado de la castidad como la virtud principal del niño y joven cristiano.

La "santa modestia" - si bien podía referirse al dominio de la altanería, la soberbia y la presunción- indicaba principalmente la pureza o decoro en los pensamientos, los afectos y las acciones. ${ }^{10}$ Dicha "virtud angelical" era lo que mejor debía guardar el alumno salesiano, de allí que la congregación ofreciera a sus alumnos una guía para lograr la santidad personal, fin último de su persistente labor evangelizadora. Dicha tarea pastoral desbordaba el catecismo para impregnar cada espacio y actividad realizada en el internado.

9 Los Principios, 2 de octubre de 1924.

${ }^{10}$ La presencia de la modestia, como virtud esencial y rectora del buen comportamiento, puede rastrearse en los tratados sobre moralidad y en los planteamientos pedagógicos desde finales del siglo XVI, asociada a la salvación del propio individuo y su obediencia a la Iglesia y al poder político (Palomo, 1997). 
Un clima de orden, respeto y observancia de las disposiciones reglamentarias era indispensable para garantizar el buen funcionamiento institucional. Desde los mismos salesianos hasta los alumnos, cada uno debía procurar "conocer, amar y cumplir el reglamento". ${ }^{11}$ Su lectura asidua familiarizaba a los ingresantes con las disposiciones que debían regular la vida en las aulas, los talleres, la iglesia, los cuartos y el trato con los superiores y compañeros. Pero más aún, excedía lo estrictamente normativo para convertirse en un manual del buen cristiano. Lejos de ser un simple listado de lo permitido y lo no permitido en el colegio, en sus páginas el niño encontraba los primeros consejos escritos para fortalecer sus virtudes cívicas y cristianas. Si bien estas recomendaciones circulaban ya a través de la palabra de los sacerdotes, en el reglamento se codificaba para tomar fuerza de ley, estableciendo criterios de amonestación de acuerdo a la falta cometida.

Junto con las blasfemias y los robos, las llamadas "impurezas" merecían el castigo más severo. Los actos de modestia, recomendados de modo especial para alcanzar la santidad, se volvían una norma cuya desobediencia debía ser penada. De manera más amplia, se fijaba una determinada política de los cuerpos destinada a cuidar el ambiente interior del colegio y corregir las desviaciones morales que pudieran traer consigo los alumnos. Así se exigía el cuidado del pudor en todo momento: observar una manera decorosa y comedida de hablar, tratar y caminar; cuidar del aseo en el vestido y el rostro; estar alegres y tranquilos; evitar los movimientos innecesarios de los hombros y el cuerpo de un lado para el otro. Esta economía gestual, que revelaba las inquietudes morales de los superiores, llegaba incluso a normativizar la forma en la cual los niños debían jugar con sus compañeros. Se intentaba suprimir todo tipo de contacto aún en las diversiones del recreo, procurando que no rozaran el cuerpo de los demás con las manos ni apoyaran el brazo en los hombros de otros, ya que se remarcaba que este tipo de conductas eran identificadas fácilmente en los hábitos indecentes de los "muchachos de la calle". ${ }^{12}$ Esta represión de los movimientos se trasladaba a las palabras y gestos verbales. No sólo los alumnos debían evitar las groserías y frases que pudieran "ofender la caridad y la decencia", sino que incluso se estimaba que a esa edad lo más conveniente era cultivar un "prudente silencio" antes que

\footnotetext{
${ }_{11}$ Reglamento para las casas salesianas, 1910, p. 4. Archivo Colegio Pío X (en adelante ACPX), Córdoba, Argentina.

12 Reglamento para las casas salesianas, 1910, p. 26. ACPX, Córdoba, Argentina.
} 
cuestionar al profesor o asistente revelando "locuacidad y atrevimiento". ${ }^{13} \mathrm{El}$ niño debía incorporar los presupuestos de la modestia cristiana, corrigiendo oportunamente cualquier defecto del carácter y esforzándose en adquirir modales suaves y decorosos, propios de un jovencito cristiano.

El reglamento del colegio, con todo su peso de ley que imponía sobre los escolares, era reforzado por toda una literatura destinada a moldear sus subjetividades. Decenas de libros, opúsculos, folletines, revistas, redactados en su gran mayoría por sacerdotes salesianos, eran la única palabra escrita a la que tenían acceso los niños. La moralización invadía el mundo de las letras y lo ponía a su servicio, convirtiéndolo en un medio para difundir el decálogo de valores del buen cristiano y honrado ciudadano. Los escritos del fundador de la congregación tuvieron un particular protagonismo en los internados. "La juventud instruida", verdadero vademécum para alcanzar la santidad, formaba la lectura de cabecera de todo alumno salesiano. ${ }^{14}$ El programa condensado en ese libro tenía la finalidad expresa de ofrecer nada menos que un método de vida, un programa de acción para que los niños lograran ser "el consuelo de los padres, el honor de la patria y futuros habitantes felices del cielo" (Don Bosco, 1952, p. 7).

A través de la literatura moral y las lecturas educativas, se proponían a los jóvenes algunos modelos de santidad, reforzados con una devoción que se exteriorizaba en imágenes, festividades especiales e itinerarios de fe destinados a purificar las almas. A lo largo de su vida, el mismo Don Bosco había redactado algunas biografías breves de jóvenes virtuosos con la finalidad de que sus modos de vivir y experimentar la religión sirvieran de ejemplo a sus muchachos e incluso a un público lector que trascendía su propia obra educativa. De todas aquellas trayectorias personales rescatadas por él y continuadas por sus sucesores, dos han gozado de una centralidad particular. En primer lugar, si bien la figura de San Luis Gonzaga ya era propuesta por la Iglesia como modelo de inocencia y virtud para los jóvenes, Don Bosco fomentará especialmente su devoción entre sus alumnos iniciando una tradición que los salesianos replicarán en cada colegio y oratorio fundado con posterioridad a su muerte. Su desprendimiento de los bienes y placeres te-

${ }^{13}$ Reglamento para las casas salesianas, 1910, p. 26. ACPX, Córdoba, Argentina.

${ }^{14} \mathrm{Si}$ en el "Reglamento" se describía el comportamiento que debían tener los alumnos en todos los espacios, en la "Juventud instruida" se enfatizaba también el tema corporal y sus movimientos, recomendando juegos y destrezas para evitar el ocio (Fresia y Nicoletti, 2014, p. 256). 
rrenales, su caridad para el prójimo, su amor a Dios sin medidas, su vida de oración, su "preciosa muerte" sin el recuerdo de haber cometido pecado alguno, eran rasgos personales que conformaban los relatos hagiográficos que circulaban en el internado salesiano. Pero de manera especial, San Luis será destacado por su "pureza angelical" y su mortificación extrema para huir del pecado. Su vida casta y su muerte en estado virginal habían sido el fruto de haber emprendido desde niño el camino de la penitencia. Don Bosco relataba con admiración cómo el joven santo había logrado vencer las tentaciones a base del ayuno a pan y agua, junto a los azotes que a su cuerpo infligía de tal manera "que sus vestidos, el piso y las paredes de su cuarto, quedaban teñidas de su inocente sangre" (Don Bosco, 1952, p. 10).

El mortificado santo del siglo xvi tuvo su continuador en la figura de otro joven que llegará a la gloria de los altares. Domingo Savio, de hecho, encarnaba muchas de las cualidades presentes en San Luis - por caso la de llevar a la tumba su "inocencia bautismal"-pero adaptadas al modelo de santidad propuesto para los alumnos salesianos. Bajo el lema "morir antes que pecar", la particularidad de la figura de Savio no radicará tanto en las virtudes de las que su vida será un ejemplo excepcional, como en el hecho de que él, por haber sido alumno de Don Bosco, mostrará un camino de santidad al alcance de cualquier oratoriano y pupilo de la congregación: "Si un compañero mío, en el mismo colegio, expuesto a los mismos y quizás mayores peligros que yo, halló, sin embargo, modo de ser fiel discípulo de Cristo, ¿ipor qué no podré yo también hacer lo mismo?" (Don Bosco, 1952, p. 9). Así, su vida será leída, sus consejos serán repetidos y sus virtudes serán glorificadas. ${ }^{15}$ Pero si el joven Savio era un ejemplo de santidad accesible a todos, lo era sólo por haberse dejado guiar por Don Bosco. De allí que la devoción a su figura también servirá para legitimar la acción de una congregación inspirada en un sacerdote que no sólo era santo, sino que además era hacedor de santos. Del mismo modo en que Domingo Savio confió en las indicaciones de su maestro y mentor, los alumnos debían dejarse guiar por los consejos de los directivos.

Las exhortaciones sobre el cuidado de la pureza y la castidad dirigidas al público infanto-juvenil por los sacerdotes salesianos incluían méto-

${ }^{15}$ El propio director del Colegio Pío X se mostrará sorprendido al ver cómo algunos alumnos habían tomado como modelo a Domingo Savio, creando un "Círculo de Estudios" con reuniones semanales y preparando homenajes al santo entre sus compañeros. Carta del Padre Gherra al Padre Inspector José Vespignani, 2 de julio de 1917. Córdoba. Caja 3. Acs, Argentina. 
dos y recetas para sortear las tentaciones. El ayuno y la oración, junto con otros gestos de devoción como besar un crucifijo o llevar el escapulario de la virgen, formaban parte de rituales destinados a conjurar las faltas contra la moral, que trascendían lo estrictamente disciplinar para convertirse en los pecados más severos. Así, los "actos impuros" no sólo eran sancionados en la dinámica institucional, sino que tomaban la senda del "castigo divino" prometiendo el infierno y la condenación eterna: “¿Cómo me dejaré arrastrar a cometer este pecado estando presente Dios, Creador y Salvador mío, quien al instante puede castigarme con la muerte? Dios, en el acto mismo en el que lo ofendo, puede arrojarme para siempre a las llamas del infierno" (Don Bosco, 1952, p. 33). Tal era la reflexión propuesta a los niños a modo de examen de conciencia en el internado salesiano.

La "impureza" era la transgresión más importante. Pero mientras que cada pecado era referido de una manera específica, este no tenía nombre. Nunca se mencionaba de manera explícita. Ni en la literatura moral, cuya profusión y tratamiento de esta problemática ha sido verdaderamente notable en la congregación, existe una sola referencia concreta a aquello que se condenaba. Palabras como "pureza", "modestia", "virtud", formaban el velo de pudor con el que se cubrían las prácticas reñidas con la castidad. Los consejos de los sacerdotes irán dirigidos así a "moderar y vencer las malas inclinaciones o pasiones interiores y en refrenar debidamente los sentidos exteriores", cuidando que su lenguaje no delate aquello de lo que se habla. Encontrar un punto medio en las palabras para no ofender la inocencia de los más jovencitos, pero sin ser demasiado vagos en las expresiones como para que el mensaje se diluya (Fierro Torres, 1960).

La prudencia en nombrar el sexo será la actitud asumida por una pastoral que intentará seguir sus aspectos, correlaciones y efectos vislumbrados en los más pequeños de los gestos, pensamientos y deseos (Foucault, 2014, p. 21). Estas sutiles expresiones, invisibles en su mayoría a los ojos de los directivos, eran expuestas a través de la práctica de la confesión. La importancia y trascendencia que los salesianos daban al "sacramento de reconciliación" entre sus alumnos retomaba el ideal propuesto por el mismo Don Bosco, quien por su afición a dicho ministerio solía ser llamado "el apóstol de la confesión" (La confesión, 1942). ${ }^{16}$ En el plan evangelizador salesiano -sintetizado en la

${ }^{16}$ Existen varias anécdotas que destacan cierta intuición de Don Bosco para examinar la conciencia de los que se acercaban a confesarse. Podemos suponer que la circulación de 
máxima presente en el escudo de la congregación, "Da mihi animas, caetera tolle" ("Dame almas y llévate lo demás")-, la confesión y la comunión eran una herramienta indispensable para la salvación y rehabilitación de aquellos que habían perdido la batalla contra los instintos. Pero en este camino hacia el "perdón divino" no bastaba con sólo tomar parte del acto penitencial. Rigurosas normativas establecían el modo de realizar una buena confesión, lo que en principio implicaba declarar al sacerdote cada una de las faltas sin omitir pecado.

La imagen construida sobre el confesor era fundamental para lograr despertar en los niños una confianza filial. El sacerdote salesiano debía ser el depositario fiel de las faltas de sus alumnos, sin importar la gravedad de estas. Según se explicaba, la ausencia de confianza "abría el camino a la hipocresía, la simulación, y lo que es peor, hasta los sacrilegios." (La confesión, 1942). Pero tanto se remarcaba la gravedad de pecar, que en ocasiones la vergüenza superaba la valentía del penitente. En las anécdotas sobre los sueños de Don Bosco, referidas con insistencia por una predica que intentaba ser lo suficientemente sugestiva como para impresionar el alma de los escolares, se repetían las imágenes de grupos de alumnos que sostenían lirios en sus manos, irradiando una luz angelical. En contraposición, los relatos incluían cuadros grotescos de niños atrapados por el demonio en forma de serpiente que no podían escapar de la angustia, la penuria y el sufrimiento. Estas eran las representaciones más oscuras del "Santo Temor de Dios" al que se aludía con insistencia en el internado y que circulaban en lecturas edificantes acerca del poder y los beneficios de la confesión (Para confesarse, 1952). Sin la presencia de un genuino dolor o arrepentimiento interior era imposible obtener la absolución de los pecados. De allí que se recomendara a los niños "excitarse el alma", pensando en imágenes que los mismos salesianos ayudaban a componer:

Para el pecador réprobo, Jesús ya no es Jesús, es decir, el Salvador; es el Juez, el juez que no conoce más que la justicia. Hiere con un castigo eterno y justísimo la perversa voluntad de ese pecador, que no puede ya convertirse. Le arroja para siempre de su vista: "iRetírate, maldito!” Lo ha maldecido; ha de-

estos relatos que destacaban la cualidad sobrenatural del santo hayan sido, en parte, una estrategia más para inducir a los niños a una confesión total de los pecados, estimulados por el temor de que cualquier omisión voluntaria fuera descubierta por el sacerdote. 
rramado sobre él toda la maldición de Dios. Esta maldición precipita al pecador a donde ella precipitó a Satanás, al abismo, al fuego eterno del infierno. Arder eternamente con todos los demonios, arder en un fuego que abrasa el alma y el cuerpo, quemarse en medio de tinieblas misteriosas, e impenetrables, arder en medio de una incomprensible desesperación, en medio de remordimientos tan atroces como inútiles, arder maldiciendo y aborreciendo a Dios, a Jesús, a María, al cielo, a todas las criaturas, hasta a sí mismo: tal es el castigo del pecado mortal en la eternidad. ${ }^{17}$

La omisión de los pecados que el joven Antonio expone en su carta es comprensible, en parte, a la luz de una catequesis centrada en la prevención por el temor. Muchas veces el silencio ante el sacerdote era un recurso frecuentado por lo niños cuyas conciencias eran estimuladas por estas escenas.

\section{LA VIDA CLAUSTRAL}

La penetración en las subjetividades de los alumnos - como forma de modelar sus conductas y prevenir las desviaciones de las normas- desbordaba el terreno meramente discursivo para saturar la organización espacial y las prácticas concernientes a la cotidianidad de la vida asilar. Los espacios construidos para albergar a los niños eran el reflejo de una arquitectura escolar cargada de preocupaciones morales. Ventanas amplias que daban a un patio interior, aulas comunicadas con amplios corredores desde cuyos ángulos podía observarse el movimiento de los estudiantes, estrados construidos en comedores y talleres sobre los que el salesiano escenificaba su presencia frente a los escolares, eran algunos de los rasgos de una edificación pensada para ser funcional a la vigilancia, el control y la asistencia.

De manera especial, esto se hacía visible en la organización de los dormitorios de los internos. La decisión de disponer las camas en un sólo salón en desmedro de cuartos para grupos más pequeños, intentaba excluir el cultivo de una intimidad concebida como peligrosa. La asistencia salesiana, fiel

17 Cómo Dios castiga el pecado mortal. En Consejos prácticos sobre las tentaciones y el pecado, Buenos Aires, s. a., Escuela Tipográfica Huerfanitos de Don Bosco, pp. 103-104. AcPX, Córdoba, Argentina. 
a los preceptos del sistema preventivo ${ }^{18}$ se extendía aún durante la noche, oficiada por un religioso convertido en verdadero gendarme de los sueños. Al dormir en el mismo salón que sus alumnos -si bien detrás de una cortina dispuesta a resguardar su pudor de posibles miradas accidentales-, el salesiano transformaba su descanso en una presencia que debía obturar cualquier indecencia motivada por la imaginación en sus educandos.

La clara oposición que se intentaba imponer entre las peligrosas libertades de la calle y la seguridad del espacio interior quedaba explícita en las rígidas condiciones del internado salesiano en cuanto a cercanía y contacto con el mundo exterior. El régimen escolar restringía las salidas de los niños, quienes solamente gozaban de un corto periodo de vacaciones matizado con ocasionales visitas de padres y tutores, a quienes se les negaba rotundamente introducir objetos que no formaran parte del ajuar reglamentario. De manera particular, se prohibía el ingreso de todo tipo de libros o revistas, reafirmando el monopolio que debían tener los salesianos en la formación de sus pupilos. La ausencia de intimidad impuesta al alumnado a través de la organización espacial, tenía su correlato en los mecanismos de comunicación epistolar permitidos con el exterior. Cada correspondencia que atravesaba los muros del internado era escrutada prolijamente por la mirada del director. La incorporación de determinados hábitos y modales, de formas de actuar y de pensar que se creían acordes a los valores propuestos, exigía encerrar a los menores en un espacio en el cual circulara un único discurso, sólido y coherente. La exclusión de cualquier disidencia, por pequeña que fuera, perseguía la internalización sin conflictos de dichos valores.

La vida retirada suponía, además, alejarse del contacto con el sexo opuesto evitando tejer cualquier lazo de familiaridad con niñas y jóvenes. En el internado se configuraba un mundo donde la mujer se hacía visible solamente a través de la figura de la Virgen María, cuya devoción fue particularmente central para Don Bosco. La prohibición del contacto con jovencitas implicaba lo físico, pero se ocupaba también de regular las miradas. Los niños debían abstenerse de ver todo aquello que pudiera atentar contra el pudor. Lógicamente que dicho régimen dejaba escasas ocasiones para que

\footnotetext{
${ }^{18}$ En el mundo de la Congregación Salesiana, el "sistema preventivo" constituye el pilar de su acción educativa. Basado en la praxis del mismo Don Bosco, se ancla en la construcción de una relación fraterna y cercana entre el alumno y el maestro como forma de prevenir la indisciplina y las transgresiones.
} 
observaran otra cosa más que aquello que los sacerdotes permitían. Era, sobre todo, en los periodos de vacaciones donde los internos experimentaban el contacto con el mundo exterior y se exponían a imágenes y situaciones que los salesianos concebían sumamente peligrosas. El ejemplo de San Luis Gonzaga apuntado en "La juventud instruida" -quien habiendo servido durante dos años en la corte de España nunca se había atrevido a ver siquiera el rostro de la princesa, e incluso no se permitía fijarse en la cara de su propia madre-, da cuenta de hasta dónde debía llegar el recato en la vista. Domingo Savio, el otro modelo de santidad joven, se había propuesto no mirar a la cara a mujer alguna para fijar por primera vez sus ojos en el "bellísimo rostro de la Madre de la pureza, María Santísima”. Los mismos biógrafos de Don Bosco tomaron nota también de esta cualidad en el sacerdote, que procuraba ser siempre reservado en la mirada ante mujeres y señoritas, demostrando incluso "cierta repugnancia al tratar con ellas, aunque fuesen parientes" (La mortificación cristiana, 1948, p. 75).

Si el exceso de apertura y disipación y la ausencia de actividades predeterminadas propios de la calle atentaban contra la moralidad, el internado salesiano se estructuraba a través de hábitos fijos y estereotipados, dividiendo las horas entre el trabajo, el estudio y la piedad. Se trataba de organizar una maquinaria escolar que permitiera una economía de tiempo y esfuerzos, evitando en lo posible las improvisaciones y los tiempos vacíos. Mantener a los niños permanentemente ocupados disminuía las posibilidades de que cometieran alguna falta, o siquiera se acercaran a sus compañeros con el peligro de que dieran rienda suelta a su imaginación mediante conversaciones inmorales: "Póngase el mayor cuidado en la asistencia para exterminar cualquier conversación o palabra peligrosa", recomendará el Padre Inspector en una de sus recurrentes visitas al Colegio Pío X. ${ }^{19}$ A través de la oración, la religión se convertía en la celadora omnipresente del orden moral rigiendo también la distribución de los horarios y actividades. Emulando la vida monástica, la santificación de las labores y tareas cotidianas se realizaba por intermedio de rezos, plegarias y jaculatorias programadas y con un sentido específico. Si la eucaristía daba inicio a la jornada de estudio y de trabajo, el día se clausuraba con las "buenas noches", ritual dirigido por el director e inspirado en una tradición iniciada por Don Bosco en el oratorio de Valdocco. Así, la última palabra permitida a los niños antes de partir a los dormitorios era la oración

19 Memoriale. Visita Inspectorial. Colegio Pío X. 1909. ACPX, Córdoba, Argentina. 
nocturna recitada colectivamente, en un esfuerzo por resguardar los sueños de los niños de cualquier pensamiento, palabra o acción reprimida durante el día.

El trabajo, el estudio, los paseos, el recreo, los juegos, la música, los ejercicios físicos, todo era atravesado por una religiosidad que le imprimía coherencia a cada acto, bajo la premisa de que se cumplía con un "Plan Divino". De allí que el pecado fuera entendido no sólo como una ofensa a Dios, sino como un impedimento real para progresar en las obligaciones cotidianas a las que el niño debía consagrarse. Esta presencia cotidiana del discurso religioso perseguía, además, la incorporación de mecanismos de autocensura en los alumnos, quienes debían entender cada falta cometida como una deshonra al colegio. La tarea de formar un buen ambiente los involucraba activamente. El mismo reglamento era claro al advertir que ante las propuestas indecentes de algún compañero, debían dar cuenta al superior rápidamente. El autocontrol y la observancia de las prácticas ajenas eran una pieza clave de la maquinaria moral puesta a punto en el internado.

La vigilancia ejercida dentro de la institución se prolongaba, incluso, en el periodo de vacaciones. A través de una carta entregada a cada pupilo, el director daba recomendaciones y consejos para conservar la virtud ante la ausencia de espacios y tiempos regulados como en el colegio. El merecido descanso podía devenir en ocio, induciendo a los niños a caer presas de hábitos impuros: "El límpido arroyuelo se vuelve pútrido y repugnante pantano cuando sus aguas se estancan. La juventud es igual. La ociosidad es la madre de todos los vicios." ${ }^{20}$ Se los instaba a apartarse de las malas compañías, las lecturas obscenas y las malas conversaciones. La reserva y la moderación en la mirada, en las conversaciones y en todas las acciones debían formar el ejemplo de pertenencia a una comunidad de jóvenes cristianos y bien educados. Y los límites de lo permitido no iban demasiado lejos. Actos comúnmente asociados a la inocencia infantil como correr, gritar, o simplemente saltar un charco en la acera, eran incluidos en el universo de lo prohibido. La disciplina en los actos privados, tan celosamente guardados en el internado, debían expresarse en público a través del orden en todos los aspectos, siendo ejemplo de civilidad y buenas costumbres.

20 Recuerdo para las vacaciones de los alumnos. Colegio Pío X. 1931. ACPX, Córdoba, Argentina. 
La intensa labor moralizante de la catequesis salesiana se conjugaba con la tarea igualmente necesaria de formar al futuro plantel de sacerdotes de la congregación. Un instrumento clave para la realización de ambos propósitos eran las llamadas "Compañías Religiosas", formadas por una selección de los mejores alumnos. Estas compañías oficiaban como auténticos "viveros de vocaciones", ya que se proponían sembrar la aspiración al sacerdocio entre el alumnado alimentando su formación cristiana. Se concebía a estos grupos como un poderoso instrumento de penetración en los niños para crear un ambiente de piedad, de estudio, de disciplina, de alegría y de orden en todos los ambientes de la escuela. Al hacer suyos los votos propios del orden sacerdotal, las cualidades que hacían a un buen clérigo debían operar también en aquellos que conformaban las compañías del "Pequeño Clero", del "Ángel Custodio", del "Santísimo Sacramento", de "San Luis" o de la "Inmaculada". La castidad sobresalía, así, como la principal virtud a cultivar. Desde las lecturas recomendadas hasta las imágenes que formaban los emblemas de cada compañía -la flor de azucena, símbolo de la pureza estaba presente en la mayoría de los escudos distintivos- daban cuenta de una especial atención puesta en el cuidado de la moral.

En una interesante descripción realizada por el Padre Inspector en una de sus visitas al Colegio Pío X, en septiembre de 1916, se ponían de manifiesto ciertas estrategias destinadas a la preparación y fomento de estos atributos en los niños. Recomendaba formar la "Compañía de María Auxiliadora”, en la que cada semana se dictaría a sus miembros una conferencia explicando el reglamento, algunos detalles de la vida, el espíritu y la obra de Don Bosco, algunos pasajes de latín, sumado a los cantos y las ceremonias. Y se proponía de manera especial que los alumnos se armaran una pequeña biblioteca de piedad con textos de San Alfonso y otros opúsculos. También se indicaba la necesidad de formar un grupo para que pasasen las vacaciones en el colegio a fin de conservar la virtud, ante el peligro que representaba el contacto con el exterior. ${ }^{21}$

Un conjunto de propuestas educativas, culturales y asociativas reforzaban esta catequesis moral tan presente en la vida asilar. ${ }^{22}$ Los "Explorado-

\footnotetext{
Argentina.

${ }^{21}$ Memoriale. Segunda Visita Inspectorial. Colegio Pío X. 1916. ACPX, Córdoba,

${ }^{22}$ Los salesianos sostuvieron una presencia activa en diversos escenarios de la vida pública y social que trascendió su faceta estrictamente escolar. La fundación de la Sociedad Católica Popular Italiana, o el trabajo con los egresados de sus instituciones a través de la
} 
res de Don Bosco" encarnaron como ninguna otra organización el espíritu evangelizador de la congregación, siempre atenta a no ceder terreno frente a otras iniciativas en el campo educativo. ${ }^{23}$ Con un estilo de fuerte inspiración marcial, los batallones de exploradores fortalecían la identidad católica y salesiana de los oratorianos e internos. Ejemplo de esto era la "Ley de Honor", que consolidaba en sus contenidos las disposiciones emanadas del reglamento del colegio, y en donde la "pureza" y la "modestia" eran virtudes que debían estar presentes en un "buen explorador que honra a Dios y su Patria”. Los niños debían combatir la pornografía, los libros inmorales, las diversiones y exhibiciones licenciosas, poniendo inmediatamente de sobreaviso a sus compañeros. Como un modelo de templanza cristiana y decoro, el explorador debía dominar sus pasiones e inclinaciones, practicando el recato en los sentidos, huyendo de las malas compañías y evitando la ociosidad. Más aún, los ejercicios físicos realizados por los exploradores se vinculaban a la formación de un determinado sujeto varonil, eliminando todo rasgo que entrara en conflicto con la masculinidad que dicha política de los cuerpos tendía a formar. ${ }^{24}$

La vida claustral, con todo su peso disciplinador, impuso un determinado sendero moral a ser transitado por quienes formaron parte del internado. En un universo tan minuciosamente regulado, las transgresiones y disidencias al poder normativo establecido podrían parecer fácilmente descartadas. Sin embargo, un examen más atento sobre las experiencias, percepciones y comportamientos de los individuos nos devuelve una imagen mucho más compleja del alcance de dicha cultura institucional. Los hechos singulares extraídos de la documentación epistolar que sustenta esta par-

organización de los Centros de Exalumnos Salesianos, son ejemplos de su voluntad por disputar el espacio público a los sectores liberales.

${ }^{23}$ El caso de los exploradores de Don Bosco es sintomático de esto, ya que pese a los esfuerzos de los mismos salesianos por marcar las diferencias con el "scoutismo", el movimiento de los exploradores fue una clara adaptación de espíritu católico de la creación de Baden Powell. Por otro lado, debe entenderse a los grupos de exploradores en el marco de un sistema pedagógico en el que, a través de otras actividades como el canto y el teatro, los salesianos fomentaban el desarrollo de la personalidad, la valorización del cuerpo y la inculcación de la higiene, la vida sana, el ejercicio físico y el deporte y la formación del gusto (Fresia y Nicoletti, 2014, p. 266).

${ }^{24}$ Para los exploradores, las actividades eran reguladas con la finalidad de controlar y prevenir ciertas emociones y sensibilidades consideradas como peligrosas. Las posiciones corporales, los movimientos y los gestos iban produciendo una masculinidad que debía evitar todo tipo de desvíos o confusiones sexuales (Scharagrodsky y Cornelis, 2013, p. 138). 
te de la investigación, pueden no ser los más frecuentes de hallar. Pero si las fuentes suelen callar o distorsionar la realidad social de las clases subalternas, los casos marginales, en apariencia anecdóticos, pueden funcionar como pruebas o indicios de una realidad escondida que, la mayoría de las veces, no es perceptible a través de la documentación general (Ginzburg y Poni, 2003, p. 89).

Allí, al nivel de los nombres propios, el entramado de la vida asilar se mostrará más poroso y menos eficiente, desnudando una realidad en la que los márgenes de acción de los niños y jóvenes, como también de aquellos que tuvieron a su cargo la tarea de resguardar la vida moral de sus educandos, se hace más aprehensible.

\section{"iCUÁN GRANDE ES LA CORRUPCIÓN EN ESTA CIUDAD!"25}

En los intersticios entre el discurso institucional y la evidencia documental se revelan las reacciones de los asistidos ante el peso de la disciplina y la hegemonía discursiva de la catequesis salesiana. La naturaleza mediada de muchos de los testimonios a los que tenemos acceso, no impide leer en ellos las palabras y los actos de los mismos niños, sus percepciones, apropiaciones, desafíos o resistencias, revelando una tensión entre los códigos morales instituidos y las diversas formas en que fueron experimentados.

La opinión de los mismos salesianos dará cuenta de las dificultades encontradas a la hora de formar una verdadera conciencia moral en los escolares. La confesión, ritual ineludible en el internado, permitía a los sacerdotes acceder a la intimidad de sus alumnos y mensurar los éxitos de su tarea evangelizadora:

El día primero de la novena por casualidad hice la conferencia a la Compañía de San José [...] porque había dejado de ocuparme de la cuestión moral, hablé en términos generales de la confianza que se debe tener a los Superiores especialmente al P. Director. Hablaron ellos con el Padre, se encontraron entre los pupilos cosas graves y, aunque tuvimos que despedir ayer un niño se arregló

${ }^{25}$ Carta del padre Tantardini al padre inspector José Vespignani, 1911. Córdoba. Caja 3. ACs, Argentina. 
mucho. Resulta lo que era, el nivel de la moralidad estaba algo bajo. Entre los externos las cosas fueron mejor y además son más francos y si pasa algo, todo se sabe casi en seguida. ${ }^{26}$

El caso de Alfonso se muestra revelador en este sentido. Quizás por su aplicación, sus buenos modales, o el trato para con sus compañeros y directivos, este alumno logró cosechar las simpatías del superior de los salesianos en Argentina en ocasión de su visita al Colegio Pío X, a inicios de 1911. Desde luego no fue el único. La voluntad siempre presente de reclutar vocaciones hacía que los directivos estuvieran particularmente atentos a individualizar a quienes mostraban cualidades para la vida consagrada. Antes de su regreso a Buenos Aires, el padre Vespignani pidió expresamente al director de Alfonso que lo preparara con más insistencia en el catecismo y el latín, a fin de enviarlo el siguiente año al aspirantado de Bernal. ${ }^{27}$ El padre Tantardini, quien no guardaba las mejores opiniones de los alumnos que no eran pupilos, ${ }^{28}$ se mostró más escéptico con respecto a las virtudes de Alfonso. Luego de inducir al joven a cumplir con la confesión de rigor, pudo confirmar sus reservas: "Después de los Ejercicios (espirituales) y después de su venida [de Vespignani] presentó malos compañeros (los de antes) y hubo entre ellos actos inmorales estando solos en una pieza de su casa, y se puede deducir que también solo. El niño estuvo en Buenos Aires. Un año o dos hace y tuvo algo con unas primas. Antes de los Ejercicios también hubo bastante entre niños y no se corrigió después." 29

Hasta allí conocemos detalles de la vida privada de Alfonso, una intimidad infantil aparentemente precoz pero quizás no tan diferente a la de otros niños. Sin embargo, podemos imaginar la dificultad que al ejercicio de su sexualidad impuso la nueva rutina del internado en la que entraría su vida, por decisión de su director. Al compartir el cuarto con sus compañeros y la mirada vigilante de los asistentes, Alfonso tendría menos ocasiones para

\footnotetext{
${ }^{26}$ Carta del padre Tantardini al padre inspector José Vespignani. 7 de mayo de 1912. Córdoba. Caja 3. ACs, Argentina.

${ }^{27}$ En el "aspirantado" se reclutaban aquellos niños de los colegios y oratorios que se mostraban dispuestos a iniciar su formación para llegar al estado eclesiástico.

${ }^{28}$ Junto al régimen de pupilos los colegios de la congregación brindaban una escolaridad común de tiempo parcial conocida como el "externado".

${ }^{29}$ Carta del padre Tantardini al padre inspector José Vespignani. 16 de diciembre de 1911. Córdoba. Caja 3. Acs, Argentina.
} 
entregarse al onanismo en la soledad de una habitación. Seguramente en el verano ya no vería a sus primas con las que supo compartir aquellos juegos que incitaron su arrepentimiento frente al confesor, para quedarse en el colegio a pasar sus vacaciones, como le fue sugerido. Eliminando las ocasiones para el pecado -la libertad de su casa, las malas compañías, el contacto con parientes del otro sexo- los directivos intentaban reformar sus hábitos, proponiéndole el camino de una vida virtuosa. Las transgresiones al orden moral, aun las más íntimas y privadas, eran susceptibles de ser detectadas, censuradas y corregidas.

Para los salesianos, sólo "frecuentando la Santa Comunión y siguiendo el consejo de sus maestros", podría Alfredo "corregir sus hábitos impuros" ${ }^{30}$ Sin embargo, las recetas espirituales no lograban del todo el efecto esperado. Mientras algunos niños se comportaban, otros en cambio se mostraban menos susceptibles a los efectos purificadores de los sacramentos. El mismo padre Tantardini -en cuya profusa correspondencia mantenida con sus superiores revelaba un particular celo hacia la moralidad de sus alumnos-, denunciaba a comienzos de 1921 que cuatro niños sobre un total de 20 entrevistados por él, habían vuelto a las andadas aun después de confesarse y comulgar. Y esta reincidencia, ya de por sí escandalosa para quien confiaba en la aplicación del sistema preventivo, era en realidad una actitud asumida con normalidad por niños que habían declarado ante el sacerdote "que desde tiempo hacían sus cosas sacrílegamente". ${ }^{31}$

Aun con la ventaja de contar con una organización institucional rígida y estrictamente reglamentada, encarrilar a los alumnos por las vías de la piedad y el temor de Dios no era tarea sencilla. De allí que las expresiones de preocupación de los encargados de realizar dicha labor, no muestren sólo los reflejos de una misión pastoral a la que se veían consagrados sino, y más aún, la persistencia en los alumnos de hábitos condenados por la disciplina moral que se les intentaba inculcar: "Estamos con 90 artesanos más o menos y 50 estudiantes. El triduo se hizo muy bien, no así el de los externos que dejan algo que desear. Es una verdadera lucha para conservar la moralidad: a veces

${ }^{30}$ Carta del padre Tantardini al padre inspector José Vespignani. 16 de diciembre de 1911. Córdoba. Caja 3. Acs, Argentina.

${ }^{31}$ Carta del padre Tantardini al padre inspector José Vespignani. 4 de abril de 1921. Córdoba. Caja 3. ACs, Argentina. 
habría que desanimarse viendo tanta falta de energía y tanta liviandad: y esto hasta en los internos especialmente artesanos." ${ }^{32}$

El rastreo puntilloso del padre Tantardini expresaba en cantidades concretas aquello que percibía con un cierto pesimismo e insatisfacción: "Los externos regular: tanto trabajo hecho el año pasado reducido a escombros. El vicio de la impureza hace estragos [...] Hace un tiempo, de 4 niños con quienes hablé, tres debían arreglar embrollos." 33 Y aunque estos "embrollos" apuntados por el salesiano hacían alusión a faltas como las de Alfonso-actos privados confesados ante las insistentes averiguaciones del sacerdote-, algunos niños daban lugar a "vergonzosos" actos públicos.

El 10 de mayo de 1913, Pablo Morassi y José De la Vega, ambos alumnos externos del quinto grado del Colegio Pío X, se encontraban en la vereda de uno de los costados de la institución esperando el tranvía que los llevara de regreso a su casa. Los "groseros juegos" practicados por los niños en la vía pública llamaron la atención del padre José Detassis, que casualmente se encontraba observando por la ventana de su cuarto cuando Pablo tocaba repetidas veces a su compañero en "partes deshonestas" y se le subía encima apretándolo con su cuerpo. Mientras, otros dos niños de primer y segundo grados presenciaban la "impúdica escena" en la que Pablo y José se daban tiempo también para proferir groserías y dirigir señas obscenas a dos jovencitas que pasaban por allí. ${ }^{34}$ Hechos como estos no eran una novedad para los salesianos. Incluso Pablo ya había dado que hablar en otras oportunidades, como cuando expulsaron a uno de sus mejores amigos por recurrir a indecencias que también lo habían involucrado a él. Los comentarios de lo ocurrido aquel día llegaron rápidamente a los directivos, que guiados por el relato del testigo y los antecedentes de Pablo resolvieron su retiro del colegio. La sanción, anclada en las disposiciones de un reglamento que no toleraba obscenidades, era coherente con la actitud asumida en otras circunstancias similares: "La lucha continua es contra las malas compañías. Sin embargo,

\footnotetext{
${ }^{32}$ Carta del padre Tantardini al padre inspector José Vespignani. 23 de marzo de 1917. Córdoba. Caja 3. Acs, Argentina.

${ }_{33}$ Carta del padre Tantardini al padre inspector José Vespignani. 6 de abril de 1915. Córdoba. Caja 3. ACs, Argentina.

${ }^{34}$ Carta del padre Tantardini al padre inspector José Vespignani. 13 de mayo de 1913. Córdoba. Caja 3. Acs, Argentina.
} 
expulsando dos o tres, todos los niños más grandes y medianos cuando se pasa algo hablan y se sabe todo y mucho [...]"35

Aun así, aquello que parecía de fácil resolución pronto hizo surgir desavenencias en las autoridades. La visita y los ruegos de la madre del alumno damnificado por la severa sanción aplicada, hicieron retractar al director quien aceptó darle una nueva oportunidad. El padre Detassis, quien como testigo directo entendía que la gravedad del acontecimiento no ameritaba obrar con tanta flexibilidad, no avaló la medida de su superior. Incluso, actuando según su "parecer de salesiano", ya había sumado al escarmiento aplicado una medida ejemplificadora para los compañeros de Pablo: luego de retirar simbólicamente su banco del aula, había entablado un edificante diálogo con la clase sobre las consecuencias de alejarse del camino de la virtud. Volver atrás suponía no sólo disminuir la gravedad de una falta para la que él pedía el mayor de los castigos, sino también perder su autoridad como maestro. Esta actitud más intransigente no tardó en confrontar con la adoptada por el director, quien entendiendo que "en ciertas familias se dan circunstancias que obligan a veces a tener más paciencia, tolerar y ver de hacer algún bien", optó por dar curso a los ruegos de la "pobre madre". ${ }^{36}$ Las posturas de los salesianos frente a las faltas de los niños, por graves que estas fueran, también conocían matices. El rigorismo de algunos que se inclinaban por la sanción ejemplificadora sin contemplaciones, convivía con un sistema preventivo que promovía una cultura de la corrección fraterna en la que el castigo, cuando no podía evitarse, debía preparar mejor la templanza del alumno ante la posibilidad de recurrir en nuevas faltas.

Los actos de Pablo no provocaron sólo desacuerdos entre los salesianos. El mismo superior de los salesianos, en su visita anual, se permitió aconsejar algunas medidas correctivas para prevenir hechos similares. Pueden advertirse allí las representaciones de la calle como lugar de perversión, indisciplina, desorden, y de los peligros que para el colegio significaban los niños cuyos hábitos hacían presumir una circulación asidua en dichos espacios: "Entre los externos hay graves peligros, por cierto elemento callejero que no ha entrado ni participa de la vida del Colegio, y está esparcido por todas

\footnotetext{
${ }_{35}$ Carta del padre Tantardini al padre inspector José Vespignani. 4 de abril de 1921. Córdoba. Caja 3. ACs, Argentina.

${ }^{36}$ Carta del padre Tantardini al padre inspector José Vespignani. 13 de mayo de 1913. Córdoba. Caja 3. ACs, Argentina.
} 
las clases [...] Debe practicarse con este elemento peligroso la acción unida del prefecto y consejero para impedir las reuniones fuera del colegio y las recíprocas influencias de estos niños en las clases." ${ }^{\text {77 }}$

La asistencia salesiana se muestra atenta, efectiva y firme al prevenir, descubrir y sancionar las transgresiones. Desborda, incluso, las propias fronteras físicas del internado. Sin embargo, cada falta descubierta, cada intento desarticulado, al tiempo que ejemplifica la capilaridad de la disciplina institucional, muestra también las grietas y las fisuras del complejo normativo construido ${ }^{38} \mathrm{Ni}$ la firmeza de un discurso obstinado en la condena del sexto mandamiento, ni la propia mirada atenta de los sacerdotes, impiden que las "impurezas" de estos niños tengan lugar. La tarea dispuesta a corregir los hábitos, modular los gestos, disciplinar los cuerpos de los niños, se descubre menos efectiva por cada transgresión que tiene lugar.

El singular pedido realizado por un joven acólito a su director, nos brinda algunas pistas en este sentido:

Como ya lo he experimentado el año pasado, el estar con los niños artesanos me parece que trae algún inconveniente para mí. Sus maneras de hacer, tan groseras; $\tan$ inconvenientes, tan peligrosas a veces, influyen mucho en $\mathrm{mi}$ ánimo, porque (quiero decirlo todo) mis antecedentes en materia de moralidad (desde niño hasta que entré en San Carlos) son desfavorables. Antecedentes de moralidad privada, si así se le puede llamar. Y al ver tantas groserías, las heridas cicatrizadas, o las llagas no del todo curadas quizás, parece quieran renovarse, aunque con la gracia del Señor siempre salí venciendo. Por eso me permito suplicar a S. R. quiera asignarme un puesto de maestro entre los niños externos. Me atengo, no obstante, a cualquier disposición de S. R. Lo pido porque me parece que allí podría estar más al seguro y más recogido. ${ }^{39}$

${ }^{37}$ Memoriale. Visita Inspectorial. Colegio Pío X. 1913. ACPX, Córdoba, Argentina.

${ }^{38}$ La historiografía sobre los alcances del control social y la normalización ha matizado las interpretaciones clásicas ancladas en la obra de Foucault sobre el éxito de los mecanismos de disciplinamiento, en las que predominaba una visión que no dejaba lugar para las ineficiencias y los efectos no previstos en instituciones concebidas como sistemas cerrados en el que todo terminaba produciendo mayor control (Caimari, 2005).

${ }^{39}$ Carta de un acólito residente en el Colegio Pío X al padre inspector José Vespignani. ca. 1920. Acs, Argentina. 
Puede leerse la preocupación que motiva la escritura de estas líneas por el otrora alumno devenido en novel maestro. El temor de no poder enfrentar con entereza los desafíos que su tarea pastoral le impone a su fortaleza espiritual denuncia, justamente, las tensiones que la propia misión civilizadora de la congregación genera, al confrontar los modales propios de quienes acusan las marcas del abandono con una cultura institucional dispuesta a corregirlos. No es casualidad que el acólito les tema a los artesanos, cuando precisamente en los talleres de la Escuela de Artes y Oficios se reclutaban los sujetos de atención referencial de una institución identificada por su sensibilidad social.

Al mismo tiempo, sus palabras insinúan los trazos de una educación recibida, de lecturas realizadas, de plegarias recitadas, que al modo de anticuerpos han formado en él una conciencia capaz de advertir el peligro moral y los riesgos de una exposición no demasiado conveniente para su ascetismo horadado por el recuerdo de un pasado libertino. El superior podía sentirse conforme de ver cómo su aprendiz había internalizado palabras, frases y expresiones que remitían a su trayecto formativo. Lo mismo que con Ángel, qué le escribía en el invierno de 1916 exponiendo inquietudes similares: "Ved, mi buen Padre, en qué situación me encuentro: Mis padres compraron una máquina de trillar, y quieren que yo vaya allá para ayudarlos. ¡Padre mío! Dadme consejos para perseverar porque si no estoy seguro de pecar, pues estoy en medio de peones y esos son mal hablados." 40

Pero quizá, las expresiones de esos niños no sólo permitan reparar en los valores adquiridos en sus años de escolares, o en la incorporación eficiente de modales establecidos para la comunicación con su superior. Hay, allí también, huellas de un afecto promovido por un maestro que entiende que su tarea trasciende la aplicación de la disciplina por medio de su autoridad, y que ha sabido cultivar una relación cercana con sus alumnos. Una amorevolezza $a^{41}$ que encuentra aquí su respuesta en el joven aprendiz, a través

\footnotetext{
${ }^{40}$ Carta de niño aspirante al padre inspector José Vespignani. 1 de diciembre de 1916. Córdoba. Caja 3. Acs, Argentina.

${ }^{41}$ En el sistema educativo de Don Bosco, la amorevolezza indica el "amor asistencial-educativo”, un complejo código de símbolos, signos y comportamientos que guiaban el trato afectuoso que el educador, con sus palabras pero más con sus actos, debía manifestar a sus alumnos. Si bien en el léxico italiano puede asumir múltiples significados, en la experiencia educativa salesiana se asociaba con el amor, la benevolencia, el afecto, la dulzura, la paciencia (Braido, 2003, p. 324).
} 
de una confianza que se muestra recíproca. Ejemplos, quizás, que nos permitan complejizar ciertas interpretaciones atentas a señalar el rígido disciplinamiento ejercido por las instituciones de asistencia y que han tendido a oscurecer la relación afectiva que, en ocasiones, podía entablarse entre los asistentes y los asistidos (Rogers, 2014).

En el caso del pequeño aspirante a sacerdote relatado al comienzo de estas páginas, tampoco es difícil observar rastros del discurso presente en los consejos de sus superiores o en la literatura moral a la que tenía acceso. Al culpar a su soberbia como el punto de inicio de los males que lo agobiaban, muestra ya la incorporación de las lecciones escuchadas y leídas en más de una oportunidad: "La tercera concupiscencia es un deseo apasionado por los honores y por la nombradía, que nos obliga sin cesar a buscar alabanzas, cumplimientos, triunfos efímeros, en fin, todo aquello que pueda alagar nuestra miserable vanidad." ${ }^{42}$

Antonio parece comprender que está en falta. Ha escuchado con insistencia que una buena confesión radica en el sincero propósito de cambio, pero su voluntad no alcanza para sostener los frutos de la penitencia: "Me confesé, ¿y sabe con quién? Con Ud. Caídas y levantadas se sucedieron sin que lograra remediar nada, hasta que caí del todo. Cometí esas repugnantes faltas de que Ud. ya se habrá enterado." ${ }^{43}$ Oculta sus actos, traicionando la confianza filial debida a sus superiores. Ha interiorizado las nociones de moral dándose cuenta de sus errores y experimentado un arrepentimiento que se muestra sincero. Aun así, las referencias explícitas a las enseñanzas recibidas muestran algo más que una cabal apropiación de la norma. En su carta confiesa sus actos, denuncia un arrepentimiento digno de quien se sabe penitente, para devenir luego en un pedido concreto que tiene que ver más con preocupaciones terrenales que con los temores a un "castigo divino":

Como le anuncié, mis padres se están por trasladar al Brasil, y yo vistas las circunstancias tendré que acompañarles [...] Voy por lo tanto a trabajar para ver si me dejan ir, unos cuantos días antes [a Buenos Aires] para poder charlar un poco con Ud. y con los demás superiores, acerca de mi vocación y

${ }^{42}$ Consejos prácticos sobre las tentaciones y el pecado, Buenos Aires, s. a., Escuela Tipográfica Huerfanitos de Don Bosco, p. 21. ACPX, Córdoba, Argentina.

${ }^{43}$ Carta de niño aspirante al padre inspector José Vespignani. 30 de abril de 1917. Córdoba. Caja 3. Acs, Argentina. 
despedirme de todos, pues yo quisiera mediante una justa reparación poder continuar mis estudios en el aspirantado de dicha nación. ${ }^{44}$

Antonio sabe que ha obrado mal. Entiende la gravedad de sus acciones. Ha pecado, pese a tantos medios empleados para evitarlo. Pero en los márgenes de libertad que las normas y códigos establecidos dejan, los asistidos también negocian, pactan y maximizan sus oportunidades (Moreyra, 2016). Al pequeño acólito, sus faltas no le impiden canalizar su remordimiento en la demanda de aquello que anhela. El arrepentimiento sincero se confunde con astucia. Antonio parece haber aprendido las lecciones, lo suficiente como para saber qué decir a su maestro.

\section{CONSIDERACIONES FINALES}

A lo largo de este trabajo se ha insistido en describir el peso de la catequesis moral presente en los colegios salesianos, expresado tanto en lo físico como en lo simbólico: las preocupaciones por el pudor y el decoro presentes en una conciencia moral que respiraban los alumnos e impregnaba toda la obra; la anulación de los espacios de intimidad; la obligación impuesta de confesar lo privado; la repetición sucesiva de ritos, plegarias, cantos y estrofas vinculadas directa e indirectamente con el cuidado de la pureza y la castidad; las imágenes ejemplares de santidad propuestas para que los escolares modelen sus actos, sueños y deseos; la búsqueda constante de la perfección cristiana como fin último de la vida del alumno salesiano; la administración correcta de los gestos más inocentes y las pulsiones más secretas; la mirada y la palabra del sacerdote, su presencia; la inspiración del "Santo Temor de Dios" y la "eterna condenación"; la regulación de lo lúdico y de las vacaciones; la estigmatización del ocio.

Pero es precisamente este gran esfuerzo invertido en regular, prohibir y vigilar lo que expresa no tanto una conquista sin fisuras de las conciencias infantiles, como los límites y dificultades de la tarea educativa de la congregación. En la prohibición de hablar en el interior de los talleres pueden descubrirse conversaciones prohibidas; en la imposibilidad de asistir solos a

\footnotetext{
${ }^{44}$ Carta de niño aspirante al padre inspector José Vespignani. 30 de abril de 1917. Córdoba. Caja 3. Acs, Argentina.
} 
los cuartos se notan los rastros de actos reñidos con la decencia; en las confesiones mensuales se oyen los susurros de los pecados callados. Cada prohibición, cada norma, cada regulación devela aquello que pretende prohibir, eliminar $\mathrm{u}$ ocultar.

Enfocar la mirada sobre el terreno de las experiencias de los individuos no supone negar el peso de las estructuras materiales y simbólicas que actúan y condicionan la agencia humana. Pero estudiar el mundo social a través de la perspectiva de los hombres y mujeres que lo componen, permite enriquecer la comprensión de esos procesos estructurales del cambio social. En nuestro caso, los testimonios de los niños asistidos permiten ver, aunque de manera difusa, aquello que el discurso institucional omite. Dentro de esa misma institución -y a pesar de ella- advertimos que otras conductas, otros comportamientos a los esperables y deseables tienen efectivamente lugar. Los mecanismos de moralización, por más efectivos que aparenten ser, se ven desbordados por gestos, palabras y miradas -sutiles e imperceptibles algunas, groseras y escandalosas otras- que no pueden ser obturadas, suprimidas, ocultadas. Y es allí, en las experiencias de Antonio, Pablo, Alfredo y la de tantos otros que ellos simbolizan, donde esa otra trama de la realidad, más compleja, difusa y esquiva, se deja ver.

\section{LISTA DE REFERENCIAS}

Braido, P. (2003). Prevenir, no reprimir. El sistema educativo de Don Bosco. Lima: ccs.

Caimari, L. (2005). Usos de Foucault en la investigación histórica. Documentos de Trabajo, 18, Escuela de Educación Universidad de San Andrés. Recuperado de http:// repositorio.udesa.edu.ar/jspui/bitstream/10908/530/1/\%5bP\%5d\%5bW\%5d\%20 DT18-Caimari.pdf

Don Bosco (1952). Juventud instruida. Buenos Aires: SEI.

Fierro Torres, R. (1960). La pedagogía social de Don Bosco. Madrid: SEI.

Foucault, M. (2014). Historia de la sexualidad. Tomo 1: La voluntad de saber. Buenos Aires: Siglo XXI.

Fresia, A. (2012). Urbanizar la campaña, modernizar las costumbres. Rodeo del Medio, una villa mendocina (1900-1915). Rosario: Prohistoria.

Fresia, A. y Nicoletti, M. A. (2014). Del cuerpo del soldado al oratorio festivo. Sociabilidad juvenil, la cuestión higienista y el cuidado del cuerpo en la educación 
salesiana a principios del siglo xx. En P. Scharagrodsky (comp.), Miradas médicas sobre la cultura física en Argentina, 1880-1970. Buenos Aires: Prometeo.

Ginzburg, C. y Poni, C. (2003) El nombre y el cómo: intercambio desigual y mercado historiográfico. En C. Ginzburg, Tentativas. México: Universidad Michoacana.

Jesen, S. y Moreno Montero, M. (2013). La escritura epistolar como registro de la experiencia de encierro y represión en las cárceles argentinas (1974-1983). Historia Actual Online, 31, 143-157. Recuperado de http://www.historia-actual.org/Publicaciones/index.php/haol/article/view/849

La confesión según el pensamiento de Don Bosco y de sus sucesores (1942). Córdoba: Instituto Clemente J. Villada y Cabrera.

La mortificación cristiana en los ejemplos y enseñanzas de San Juan Bosco (1948). Santiago de Chile: Instituto Teológico San Juan Bosco.

Landaburu, A. (2012). Niñez, juventud y educación: el proyecto salesiano en Tucumán. 1916-1931. Tucumán: EDUNT.

Lenti, A. (2013). Don Bosco. Historia y carisma (3 tt.). Madrid: ccs.

Moretti, N. (2014). Buenos cristianos y honrados ciudadanos. La obra salesiana y la cuestión social. Córdoba, 1905-1930. Córdoba: Centro de Estudios Históricos "Prof. Carlos S. A. Segreti”.

Moreyra, B. (2014). El revival de la historia social en la primera década del siglo xxi: ¿retorno o reconfiguración? Historia da Historiografía, 15, 168-186. DOI: 10.15848/ hh.v0i15.740

Moreyra, B. (2016). Los asistidos como grupo social en los espacios asistenciales en Córdoba (Argentina) 1900-1930: la conformación de una identidad. Delaware Review of Latin American Studies, 17(2). Recuperado de http://udspace.udel.edu/ handle/19716/19838

Nicoletti, M. A. (2008). Indígenas y misioneros en la Patagonia. Huellas de los salesianos en la cultura y religiosidad de los pueblos originarios. Buenos Aires: Ed. Continente.

Oraciones y ejercicios de piedad para los colegios salesianos (1949). Buenos Aires: SEI.

Palomo, F. (1997). "Disciplina christiana”. Apuntes historiográficos en torno a la disciplina y el disciplinamiento social como categorías de la historia religiosa de la alta edad moderna. Cuadernos de Historia Moderna, 18, 119-136.

Para confesarse con fruto. Pensamientos, consejos y ejemplos de San Juan Bosco (1952). Buenos Aires: Escuela Tipográfica Huerfanitos de Don Bosco.

Revel, J. (2015). Presentación: la construcción de lo social. En J. Revel (dir.), Juegos de escalas. Experiencias de microanálisis. San Martín: UNSAM. 
Rogers, H. (2014). Kindness and reciprocity: Liberated prisioners and christian charity in early nineteenth-century England. Journal of Social History, 47(3), 721-745. DOI: $10.1093 /$ jsh/sht106

Scharagrodsky, P. y Cornelis, S. M. (2013). Modelar la masculinidad cristiana: prácticas corporales en los exploradores argentinos de Don Bosco (primera mitad del siglo xx). En A. M. Rodríguez (ed.), Estudios de historia religiosa argentina. Rosario: Prohistoria.

Sosenski, S. y Rojkin, I. (2016). Presentación. En Dossier: Los niños como actores sociales en la historia de América Latina (siglos XIX-XX). Trashumante, 8, 8-9. DOI: 10.17533/udea.trahs.n8a01

Vespignani, J. (1922). Circulares, cartas, avisos. Para uso de los salesianos de la Inspectoría Argentina de San Francisco de Sales. Buenos Aires: SEI.

Zapiola, M. C. (2010). Espacio urbano, delito y "minoridad": aproximaciones positivistas en el Buenos Aires de comienzos del siglo xx. Revista Educación y Pedagogía, 22(57), 51-72.

\section{OTRAS FUENTES}

\section{Archivos}

ACS Archivo Central Salesiano, Argentina.

ACPX Archivo Colegio Pío X, Córdoba, Argentina.

\section{Hemerografía}

Los Principios. 